\title{
Addressing Today's challenges in automotive remanufacturing
}

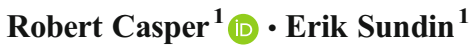

Received: 26 June 2017 / Accepted: 15 June 2018 /Published online: 3 July 2018

(C) The Author(s) 2018

\begin{abstract}
Automotive remanufacturing companies are nowadays facing a wide range of challenges. Typical challenges from the point of view of suppliers, producers and customers. Several process steps are analysed and problem fields are dissected: From the core management, to disassembly and cleaning to machining and testing. The main fields of challenges analysed in this paper are: the vagueness in respect of fiscal value, environmental regulations and taxation of core parts, the important need for a continuing qualification of staff and engineers, an efficient core management, the adaption of pricing models and the competence to handle the growing variety and complexity. The focus of this analysis lies on activities of the independent after-market (IAM) for remanufactured products.
\end{abstract}

Keywords Remanufacturing $\cdot$ Automotive $\cdot$ Mechatronics $\cdot$ Electronics $\cdot$ Design for Remanufacturing $\cdot$ Core management $\cdot$ Circular economy

\section{Introduction}

Automotive remanufacturing is of growing importance within the automobile industry. Nowadays every OEM has programs with remanufactured parts and their market volume is growing [12]. Targeting for an earlier end of production (EOP) of new spare parts, OEMs establish more and more remanufacturing systems. Reasons for this are rising production costs per produced part as an effect of decreasing production output. In many cases production lines and the resources (e.g. staff, machines) are also needed for newer production lines [9]. Like all other branches the remanufacturing companies have to address challenges to stay competitive. In this paper today's most important challenges are highlighted. The aim of this paper is to put important remanufacturing-specific challenges together and create awareness of all responsible

Erik Sundin

erik.sundin@liu.se

1 Division of Manufacturing Engineering, Department of Management and Engineering, Linköping University, SE-58183 Linköping, Sweden 
parties involved and focuses herby on the automotive car remanufacturing industry in Germany. The focus of this analysis lies on activities of the independent after-market (IAM) for remanufactured products.

Where possible, challenges are evaluated and potential solutions are given. In the end a recommended course of actions is given and an outlook concludes this paper.

\section{Methodology}

To obtain and verify the necessary information for the above mentioned problems, different methods and techniques have been applied:

1. Relevant, available literature in connection with this matter was studied.

2. Semi-structured interviews with several experts and managers at remanufacturing companies have been conducted (see Table 1).

3. The data from step 1 and 2 was aggregated and clustered.

4. The clustered data was analysed and samples were highlighted.

5. The data was evaluated and recommended courses of action were given.

\section{Remanufacturing and politics}

Like every other industry as well, the remanufacturing business is subject to local, national and international restrictions, regulations and laws. In general some facts can make remanufacturing business in the interaction with authorities and the state more complicated in comparison to other businesses:

Definition of the status of cores: The interpretation of the status of cores is often a matter of discussions. Can cores be seen as a used spare part? As old metal? As a scrap part? As hazardous waste? The particular interpretation of the state has a strong influence on the remanufacturing business, as these questions are strongly linked to taxation regulations and import/export terms, i.e. with regard to waste legislation etc [2].

Table 1 Environmental sustainability indicators used by six different sources

\begin{tabular}{|c|c|c|}
\hline Interviewee & Company/Organisation and function & Content \\
\hline $\begin{array}{l}\text { Prof. Dr. Carsten } \\
\text { Bücker }\end{array}$ & BU Drive $\mathrm{GmbH}$, CEO & $\begin{array}{l}\text { General challenges in today's } \\
\text { remanufacturing }\end{array}$ \\
\hline Achim Birr & BU GmbH, Director Sales & $\begin{array}{l}\text { Remanufacturing market, sale challenges, } \\
\text { logistics challenges, customer's needs }\end{array}$ \\
\hline Willi Ketz & $\begin{array}{l}\text { Schmitz + Krieger } \mathrm{GmbH}, \\
\text { Plant Manager }\end{array}$ & Technical challenges in remanufacturing \\
\hline Volker Münster & $\begin{array}{l}\text { Hans Hess Industrietechnik GmbH, } \\
\text { General Manager }\end{array}$ & $\begin{array}{l}\text { Technical challenges in remanufacturing, } \\
\text { re-engineering, core sourcing }\end{array}$ \\
\hline Helmut Spangenberg & $\begin{array}{l}\text { Erasmus + Willms GmbH, General } \\
\text { Manager }\end{array}$ & Technical challenges in remanufacturing \\
\hline
\end{tabular}


Definition of status of remanufactured exchange parts: Equivalent to the discussion concerning the status of cores (see above), there are different points of view on how to evaluate a remanufactured exchange part. Can it be seen as a new spare part? As a used spare part? As a repaired spare part? Accordingly this has influence on taxation regulations and import/export terms. But moreover the important field of duration of warranty is affected.

Special tasks around the remanufacturing-specific transformational process: The remanufacturing process consists of process steps which differ from other transformational processes. Some of these steps are of special interest to authorities and regulations, often dealing with environmental task:

- Used parts are being transported - often over long distances - and are usually contaminated with material and liquids which could harm the environment. Therefore transport packaging has to therefore meet other, more strict demands.

- In the process step "core disassembly" the above mentioned materials and liquids have to be handled, stored and disposed of according to the respective regulation of the country. Very often authorities are demanding a complex and time-intensive reporting and communication process.

\section{Remanufacturing and society}

The society in total can be seen from two perspectives:

On the one hand it can be seen in our model as a counterbalance to politics and industry. A party which evaluates the actions of the other two parties in a critical form. In this respect the actual attitude of the society towards remanufactured products is of interest. This attitude is highly dependent on the actual understanding and evaluation of "Green Business" and the interest in problems and questions relating to environmental standards. Last but not least the actual overall economic situation within a society is of high importance for the remanufacturing industry, too. These views on remanufactured products are very important for remanufacturing companies, as the society is the potential client of every company operating in this business. Even if companies in the short term are just dealing with OEcustomers: A product which has no acceptance within a society is non-marketable in the medium term. To generate, conserve and extend this attitude is an important challenge of the complete remanufacturing industry. Remanufactured parts have to be seen from the customer side as environmentally and economic worthwhile [5].

On the other hand the society and the actual development in itself affect the framework of the potential activities of remanufacturing companies. Important developments within the society with influence on remanufacturing are [12]:

- Even though the total number of registered cars in Germany is rising constantly, the average mileage per car stays on the same level. Breakdowns of parts are highly dependent on usage and the spare part market does not grow equivalently to the total car market.

- The numbers of cars per family rises. But the total mileage per family does not rise. The result is a lower mileage per car with the same effect as described in the first point.

- The significance of one's own car decreases more and more, especially among young people in cities. Previous generations were seeing their car as a status symbol, whereas 
today's younger generation set different priorities. The switching to public transport and car sharing systems is resulting in a leak of potential customers for the automotive remanufacturing industry.

\section{Technical trends and its influence on remanufacturing}

Some of the latest trends in the automotive industry were disadvantageous for the automotive remanufacturing industry. Some volitional, intended from OE-side, some unintentional.

Trend 1: Products last longer The composition and quality of materials as well as techniques and procedures of production have improved significantly in the last years. Moreover improvements in the field of operation liquids and the usage of earlywarning systems as for example ODB (On-Board-Diagnosis-System) help to prevent fatal breakdowns of parts. All these facts have led to a decrease in the failure rate of mechanical parts, which can in general be seen as a positive trend. The side-effect is that the need for exchange parts gets smaller and the competition in the remaining market gets bigger [1].

Trend 2: Electronic components are taking over more and more functions in modern cars This development has two major effects in the remanufacturing business:

- These new components are offering a new field of activity for remanufacturing companies. As all other parts too, electronic components break down and spare parts are needed.

- A lot of the traditional remanufacturing companies are today not prepared for this new challenge or are in the process of building up knowledge and competences in the field of electronics including core management, spare part sourcing, technical information and the supply of operating software [9].

Trend 3: Remanufacturing-unfriendly products are increasing Even though it is known and desired from OE-side, that certain components have to be opened and/or disassembled, the design does not respect this. In addition $[4,6]$ :

- Some materials in the construction of engine blocks (e.g. Nikasil, Alusil) make it hard or even impossible to machine and remanufacture them in the classical way by drilling and honing the cylinders.

- The lightweight construction of engine blocks, that is getting more and more common, makes drilling and honing of cylinders hardly possible, too, as necessary tolerances can no longer be complied.

- Parts are often constructed in a way that a non-destructive disassembly is impossible.

- Products are becoming more complex and more heterogeneous: Components sometimes contain hazardous parts (e.g. batteries in electric tooth brushes). 


\section{Challenges in connection with suppliers in the automotive remanufacturing industry}

The demand for remanufactured parts is very often announced from OE-side at a very early point in the product life-cycle, but not so the spare part logistic from the OEM. The production line of the new part is running, but the after-sales-department has not yet generated articles in the ERP.

Moreover these parts are not stored in the central warehouses. The original manufacturers of the spare parts are at that point only supplying the production lines. Contracts between the spare part manufacturer and the after-sales-organisation of the OEM are most often nonexistent. Frequency of delivery, form of packaging, content and scope of delivery are not adaptable to spare part demand of remanufacturers. These are reasons spare parts can often not be sourced, even though they are still produced and used in serial production lanes. In many cases the way of packaging and the packaging size is not adaptable to remanufacturing processes. This effect can occur in two characteristics:

- In a serial production of remanufactured parts: Parts are sometimes available on the market but are provided in a form which is not adaptable to serial processes. Delivery batches are too small, processes in the central warehouse logistics of the supplier are not designed for larger demands of a small quantity of spare part numbers and the form of packaging is adapted only to small bulk usages.

- In small batch productions and in 1-to-1-remanufacturing: A contrary effect can be seen in the remanufacturing process in small batches or of a single part (1-to-1-remanufacturing; batch size 1). Spare parts on the market are not available in the required quantity.

\section{Challenges of the process step "Core management" in the automotive remanufacturing industry}

The main issues concerning core management are nowadays:

- Even if the planned output is known, additional core parts have to be obtained to replace missing returns from customers. Minimum inventory levels have to be held up high, even if this is non-economical.

- The quality of the core parts planned to return from customers is not clear. The effect is the same as described in the first point.

- The need and value for core parts is not known or not respected by all responsible persons on OE-side.

- The complexity of the available core parts is leading to an immense effort. Single part numbers are very often available in a wide range of revision levels and change status'. This complexity has to be managed, the identification gets severe and inventory levels rise.

- The specific date a core part is returned from the customer and available for the production process is hard to define. Planning systems have not yet found reliable techniques to forecast this point of time sufficiently. Modern electronic systems are discussed and tested to improve this fact [8]. 


\section{Challenges in the field of core reception, identification and first visual checks in the automotive remanufacturing industry}

This procedure is the first value added process step in the automotive remanufacturing business. Insufficient execution of this process is leading to faulty identified parts and incorrect quality decisions which are leading to problems in the production process. Here today's challenges are especially: An important challenge is to handle the immense variety. A research lately made by a German university came to the conclusion that the highest number of identified effects for successful remanufacturing lies in the field of handling variety and resulting complexity. A remanufacturer could and should strive for a unification of dress levels. It is cheaper to plug or bore an inlet/outlet compared to ordering and warehousing a diversity of new short-blocks with the only difference in this bore.

According to one of the interviewed remanufacturing company mangers the following critical effects of remanufacturing can be illustrated in as Fig. 1 shows [11]:

\section{Challenges in the field of disassembly, cleaning and second inspection in the automotive remanufacturing industry}

In the process step of disassembly, cleaning and second inspection challenges in the matter of design, technical evaluation and environmental regulations have to be accomplished. These are first and foremost:

- Parts are in some cases not designed for disassembly.

- Core parts are most often heavily contaminated with oil, fat, particles, oxide and other operational liquids. Kind and level of contamination are often unknown before receiving the parts. The cleaning process itself is a great challenge for the companies and is often seen as the main competence and a unique feature of remanufacturing companies [6].

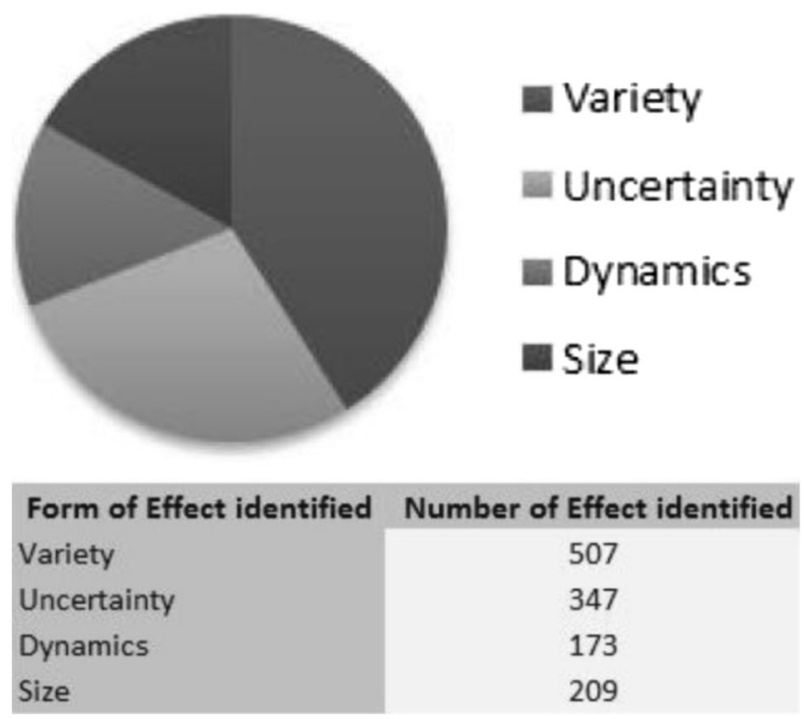

Fig. 1 Identified critical effects on remanufacturing 
In Fig. 2. an example is shown of a product that needs to be assembled in a clean environment in order not to be contaminated.

\section{Challenges in the transformational processes of automotive remanufacturing companies}

The transformational process, which is in the main the remanufacturing production process, is the process step with the highest added value. In fact it is not only one process. Depending on the product and the depth of added value it can consist of a larger number of processes. It is the main competence of the complete industry branch and the field in which methods and technologies are adapted which define them from comparable industry branches. Nevertheless several challenges have to be accomplished here [10]:

For various reasons situations occur where automotive parts are not yet or no longer available. Here remanufacturing can profit and generate interesting business opportunities.

Even though production planners on OE-side work with complex systems to plan for the demand of automotive parts up to the end of delivery obligation (EDO), scarcities in stock levels or the total loss of the ability to deliver occurs. Remanufacturing companies can become stronger if they can successfully manage the main challenges in connection with this business model [3]:

- Locate and collect core parts in the correct quality.

- Develop and implement a secure remanufacturing process.

- Source spare parts.

- Obtain data, technical information and drawings.

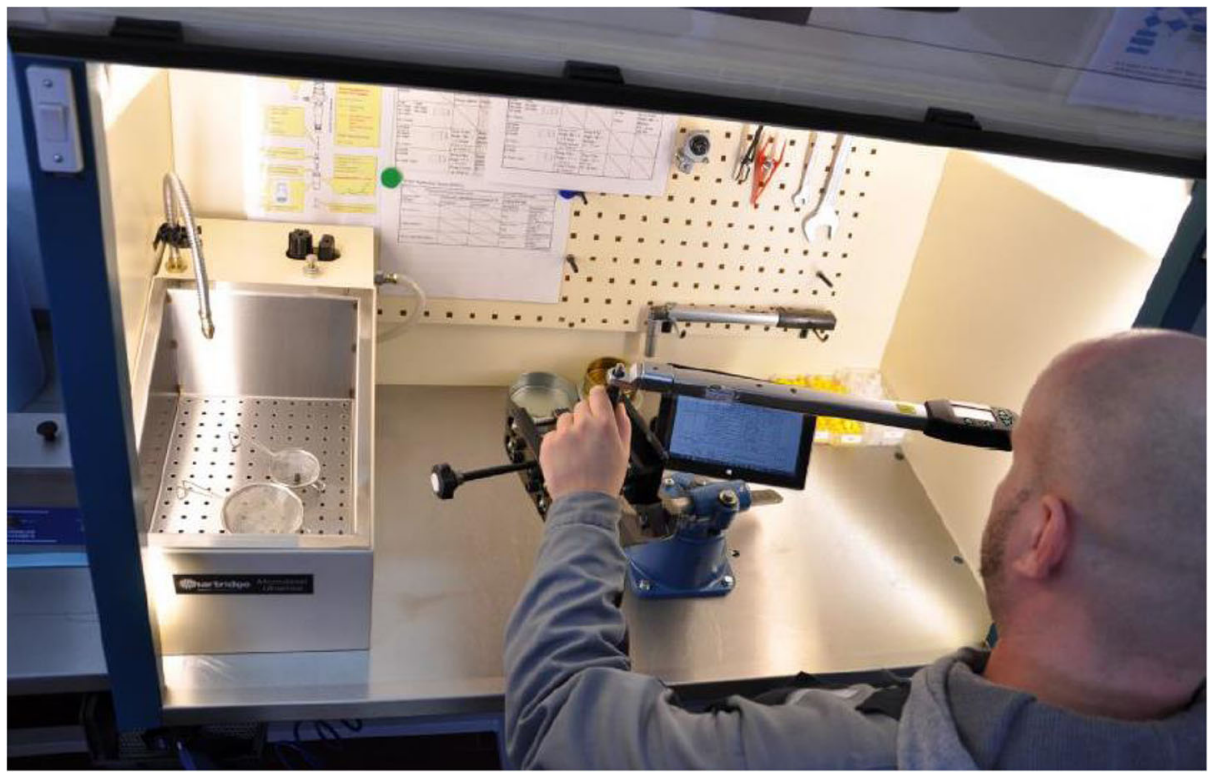

Fig. 2 Assembly of a remanufactured injector at a German automotive remanufacturing company using a clean cabinet, over pressure and filters capable of particle filtration down to $0,5 \mu \mathrm{m}$ 
- Reverse engineering, if data from OE or genuine supplier is not available, incl. Material analysis and potential improvement and dimensional analysis.

A big challenge is the remanufacturing of electronic and mechatronic automotive parts. These complex systems have to be understood, techniques for testing and repair have to be developed and sources for spare parts have to be found. For an industrial branch, which was historically mainly active in the field of mechanics, a hard step into the digital age. A step which has to be made if not to become economically and technologically backward.

Dress levels of automotive remanufactured parts have changed in the last years. It was most common to build and sell engines in the dress level "long-block" (cylinder block, oil pan, cylinder head and valve cover). This was a dress level which made it possible to proceed a hot test on an engine test bench at the end of the production process. Nowadays many OEs are not willing to pay for an engine test on a long block anymore. They await that QM assures quality as the OEMs new production does (or should). Furthermore smaller dress levels - especially short-block (cylinder block) - get more and more common because of cost reasons. Classical testing procedures are not adaptable here or the effort of hot testing would be too high. Nevertheless testing methods for short-blocks are in general technically possible and could ensure integrity and functionality.

More and more often engineers in the production process are confronted with materials or OE-production procedures which make remanufacturing harder or even impossible. For example: Crankshafts hardened in a special way which cannot be machined. Fractional conrods which can no longer be machined, coated cylinders cannot be drilled and honed with conventional machinery [7].

\section{Challenges in connection with customers in the automotive remanufacturing industry}

As highlighted in section 6 the suppliers of spare parts and the customers for remanufactured parts are very often identical. Nevertheless four challenges are just customer-related and are described in this section:

1. As in every other business, remanufacturing companies certainly have to deal with competitors. A fact which forces companies to improve their products, business processes and services. In the remanufacturing industry a competitor often plays an important role, which can hardly be beaten: The production lines for new parts. In most of these cases the prices for remanufactured parts cannot compete with the price of the new part. These changes drastically at the End of Production (EOP).

2. Potentially a very positive effect for remanufacturing companies is the growing warranty market. This has mainly two reasons; Firstly, since the reformation of the European law of obligations in the year 2000 all companies have to confer their customers two years warranty. As companies had to prolong their warranty phases, the warranty market grew. Secondly, several OEM voluntary prolonged their warranty phases. Warranty phases between five and seven years are conferred, especially among Asian OEMs.

3. Especially after the crisis in the year 2008 the OE-industry became very cost-conscious. They expect a high efficiency and high usage of production capacity and practice cost pressure. 
4. The opportunity to sell the remanufacturing concept is sometimes a great challenge. Origin, experiences, attitude and philosophy of the responsible person on the customer's side, as well as the company policy are very essential in order to place an offer or even a contract. An important challenge for the remanufacturing industry is here to go on promoting the environmental, technical and economic advantages of remanufactured parts.

\section{Conclusion and recommended course of action}

It becomes very apparent that beside the need to overcome several challenging difficulties presented in this paper; many challenging opportunities for this industry exist and should be used. Especially the following six recommendations can be given to companies operating in this field:

1. Remanufacturing companies should use active lobbying in a positive sense on political basis to strengthen automotive remanufacturing. This would help to find and fix clear definitions of the status of core parts. As a result the described vagueness in respect of fiscal value, environmental regulations and taxation of core parts could be avoided.

2. Companies remanufacturing automotive parts should focus on a continuing qualification of staff and engineers. Especially in the field of the latest development in electronics the staff should be schooled and encouraged to broaden their horizon. Engineers should have the knowledge, the ability and the courage for innovative solutions in engineering to overcome technical obstacles.

3. A focus on an efficient core management lays the basis for a successful overall business with automotive remanufacturing parts. It should be actively tracked instead of just reacting to a given demand.

4. A good, open, frank and objective exchange between remanufacturing companies and their customers should be the aim of every business relationship. A lot of detailed, remanufacturing-specific questions have a strong need of explanation for people not familiar with this business model.

5. Remanufacturing companies should know and react to the positive and negative challenges because of the growing variety and complexity. Specialisation versus generalization.

6. Remanufacturing companies profit from an engagement in very early phases of product development to retain and improve possibilities to disassemble and remanufacture parts. This engagement demands the willingness as well as the comprehension on OE-side (see section 9).

Remanufacturing companies regarding these recommendations have good opportunities to operate in an attractive, growing industry. Some challenges are hard as they are combined with investments in staff, knowledge and machinery. Some smaller companies without the possibilities to react to the actual challenges will disappear from the market. But all other automotive remanufacturing companies being up-to-date today, cannot adopt a laid back attitude. 


\section{Future research}

Further research will proceed in the described major challenges to gain a better understanding and solutions. At the moment general remanufacturing market research, focused research on electronic data transfer in the remanufacturing industry and research in the field of transportation challenges are emerged."

Acknowledgements The authors wish to thank their interview partners for their kind support. Special thanks to the company BU Drive for the data and information.

Open Access This article is distributed under the terms of the Creative Commons Attribution 4.0 International License (http://creativecommons.org/licenses/by/4.0/), which permits unrestricted use, distribution, and reproduction in any medium, provided you give appropriate credit to the original author(s) and the source, provide a link to the Creative Commons license, and indicate if changes were made.

\section{References}

1. Automotive Remanufacturing (2010) - A Global Strategic Business Report, San Jose

2. Battle, JD., (2000) Aftermarket Business, "Quality workmanship continues to grow reman industry", San Diego

3. Matsumoto, M., (2012) "Design for Innovative Value towards a sustainable society", Dordrecht

4. Nikolaidis Y (ed) (2013) Quality Management in Reverse Logistics. Springer-Verlag, London

5. Östlin J, Sundin E, Björkman M (2009) Product life-cycle implications for remanufacturing strategies. J Clean Prod 17(11):999-1009

6. Sundin E, Elo K, Lee HM (2012) Design for automatic end-of-life processes. Assem Autom 32(4):389-398

7. Universität Bayreuth, Chair Manufacturing and Remanufacturing Technology, (2012) "Reverse supply chains within automotive remanufacturing", Bayreuth

8. University of Sussex, (2017) School of Engineering and Informatics, Engine Testing and Modelling, Sussex

9. Weiland FJ, FJW Consulting, (2009) "Remanufacturing new and future automotive technologies", Cologne Germany

10. Weiland, Fernand J. (2012) "European Automotive Remanufacturing - Technical Trends \& Market Development", Cologne, Editions FJW Consulting

11. Westermann, Hans-Henrik, Fraunhofer Projektgruppe Prozessinnovation, (2012) Researcher, Managing Complexity in Remanufacturing Companies, Bayreuth

12. Wolf, Günter, VMI e.V, (2010) "German market for remanufactured engines", Budapest 